\title{
Awareness of deficits in traumatic brain injury: A multidimensional approach to assessing metacognitive knowledge and online-awareness
}

\author{
FIADHNAIT O'KEEFFE, ${ }^{1}$ PAUL DOCKREE, ${ }^{1}$ PAULINE MOLONEY, ${ }^{1}$ SIMONE CARTON, ${ }^{2}$ \\ AND IAN H. ROBERTSON ${ }^{1}$ \\ ${ }^{1}$ Trinity College Institute of Neuroscience and Department of Psychology, Trinity College, Dublin, Ireland \\ ${ }^{2}$ Department of Clinical Neuropsychology, National Rehabilitation Hospital, Dun Laoghaire, Dublin, Ireland \\ (Received May 31, 2006; Final Revision August 7, 2006; Accepted August 9, 2006)
}

\begin{abstract}
Recent models of impaired awareness in brain injury draw a distinction between metacognitive knowledge of difficulties and online awareness of errors (emergent and anticipatory). We examined performance of 31 Traumatic Brain Injury (TBI) participants and 31 healthy controls using a three-strand approach to assessing awareness. Metacognitive knowledge was assessed with an awareness interview and discrepancy scores on three questionnaires-Patient Competency Rating Scale, Frontal Systems Behavioral Scale and the Cognitive Failures Questionnaire. Online Emergent Awareness was assessed using an online error-monitoring task while participants performed tasks of sustained attention. Online anticipatory awareness was examined using prediction performance on two cognitive tasks. Results indicated that the TBI Low Self-Awareness (SA) group and High SA group did not differ in terms of severity, chronicity or standard neuropsychological tasks but those with Low SA were more likely to exhibit disinhibition, interpersonal problems and more difficulties in total competency. Sustained attention abilities were associated with both types of online awareness (emergent and anticipatory). There was a strong relationship between online emergent and online anticipatory awareness. Metacognitive knowledge did not correlate with the other two measures. This study highlights the necessity in adopting a multidimensional approach to assessing the multifaceted phenomenon of awareness of deficits. (JINS, 2007, 13, 38-49.)
\end{abstract}

Keywords: Impaired self-awareness, Traumatic brain injury, Neuropsychological deficits, Error-monitoring, Executive functions, Behavior

\section{INTRODUCTION}

Impaired self-awareness (ISA) of deficits following Traumatic Brain Injury (TBI) has been identified as a significant factor in determining successful outcome, in terms of rehabilitation (Lam et al., 1988), vocational status (Sherer et al., 1998b; Wise et al., 2005), functional independence, maladaptive behavior (Trudel et al., 1998) and caregiver distress (Prigatano et al., 2005). Previous research investigating impaired awareness of deficits in TBI has indicated that TBI patients are more accurate at assessing their strengths and limitations for concrete and observable defi-

Correspondence and reprint requests to: Professor Ian H. Robertson, Trinity College Institute of Neurosciences, Trinity College, Dublin 2, Ireland. E-mail: iroberts@tcd.ie cits such as physical limitations or difficulties, activities of daily living and memory problems (Fleming \& Strong, 1999), whereas impaired awareness of deficits becomes more evident for abstract or higher level cognitive functions, personality changes, social interactions, and emotional control (Fischer et al., 2004a; Fleming \& Strong, 1999; Prigatano, 1996; Prigatano et al., 1990).

There have been mixed findings in studies examining the neurocognitive correlates of awareness. Severity of injury has shown some relationships with self-awareness deficits (Prigatano, 1999b), but many other studies have not found any associations (Allen \& Ruff, 1990; Anderson \& Tranel, 1989; Prigatano \& Altman, 1990). Other studies found associations in the opposite direction to that predicted (Sawchyn et al., 2005; Sherer et al., 1998c) or mixed results depending on which measure of severity was used (GCS or PTA) 
(Prigatano et al., 1998). Poor performance on intelligence tests has been associated with self-awareness in TBI, with lower post-injury verbal intelligence associated with greater impaired awareness (Anderson \& Tranel, 1989). However, this relationship was not found in other studies (Ownsworth et al., 2002; Trudel et al., 1998), and individuals with intact intellectual functioning have also shown deficits in impaired awareness (McGlynn \& Schacter, 1989). Executive dysfunction has been associated with ISA in many studies (Allen \& Ruff, 1990; Hart et al., 2005; Noe et al., 2005; Ownsworth et al., 2002), but this association was not found, or only partially replicated in others (Bogod et al., 2003; Trudel et al., 1998). In studies that have found this association, the types of executive functioning that have been associated with aspects of awareness include ability to shift-set or form abstract concepts (Noe et al., 2005), planning abilities (Coben et al., 1995), mental flexibility (Coben et al., 1995; Trudel et al., 1998), idea generation or fluency (Coben et al., 1995; Ownsworth \& Fleming, 2005), selfregulation and social interaction skills (Bogod et al., 2003; Ownsworth et al., 2002), sustained attention (McAvinue et al., 2005), and reasoning abilities (Malec et al., 1997; Ownsworth et al., 2002). Memory function including WMS-R General Memory Index (Trudel et al., 1998) and delayed recall (Noe et al., 2005; Trudel et al., 1998) have also been identified in some studies as a significant predictor variable for self-awareness.

Functional or clinically based models of ISA have been developed in an attempt to characterize this complex phenomenon and to guide rehabilitation. At a functional level, Crosson et al. (1989) divided awareness into intellectual awareness, which represents a patient's ability to recognize his/her deficits or impaired functioning, emergent awareness, which represents a patient's ability to describe their difficulties as they are happening, and anticipatory awareness, which represents a patient's ability to predict when difficulties will arise because of their deficits. The hierarchical structure of this model has been criticized (Abreu et al., 2001; Toglia \& Kirk, 2000), and more interactional models have differentiated between metacognitive knowledge or declarative knowledge about one's abilities, which would incorporate elements of intellectual awareness and online monitoring of performance during tasks, which relates to emergent awareness and anticipatory awareness (Toglia \& Kirk, 2000).

There is little consistency in the literature regarding measures of awareness, with a wide variety of methods adopted and some controversy regarding the best approach (Fleming et al., 1996; Hart \& Sherer, 2005; Wise et al., 2005). Methods include comparing self-ratings to significant other or clinician ratings, such as the Patient Competency Rating Scale (PCRS) (Fleming et al., 1996; Prigatano et al., 1986; Sherer et al., 1998a), interviews (Fleming et al., 1996; Ownsworth et al., 2000), observation of actual task performance (Hart et al., 1998), comparison of patients' reports to neuropsychological performance (Allen \& Ruff, 1990; Anderson \& Tranel, 1989), comparison between patients' predictions of performance and actual performance (Gauggel et al., 2002; Fischer et al., 2004a) and more recently onlinemonitoring of errors (McAvinue et al., 2005; O' Keeffe et al., 2004). A number of researchers have highlighted the importance of using a number of different measures to assess the multi-faceted concept of self-awareness of deficits (Fischer et al., 2004a; Fleming et al., 1996). Ownsworth et al. (In Press) point out that the range of different indicators of awareness may not capture the complexity of the construct and Markova and Berrios (2001) suggest that each assessment approach examines a different "object of insight" and that unawareness therefore varies according to assessment type. The numerous inconsistencies in the literature regarding neuroanotomical, neurocognitive, and clinical correlates of awareness may be explained by the fact that conclusions are frequently made based on limited perspectives on unawareness derived from assessment of a single specific "object of insight" (Ownsworth et al., In Press). A richer, multidimensional approach to assessment of awareness has been called for recently, that can inform theoretical models, develop clinical methods of assessment, develop tasks suitable for neuroimaging studies of self-reflection and awareness, and guide rehabilitation of this complex phenomenon (Fischer et al., 2004a; Ownsworth et al., In Press; Prigatano, 1996; Sherer et al., 2005; Toglia \& Kirk, 2000).

The goals of the present study were to incorporate Toglia and Kirk's (2000) model into a comprehensive, multidimensional approach to assess awareness in patients with Traumatic Brain Injury. Therefore, awareness was assessed in terms of metacognitive knowledge (intellectual awareness) and online awareness (emergent and anticipatory awareness). Furthermore, we hoped to clarify which neuropsychological abilities are associated with awareness based on a detailed neuropsychological examination of each participant.

\section{METHOD}

\section{Participants}

Thirty-one adults with traumatic brain injury (TBI) took part in this study. Exclusion criteria for all participants included a pre-trauma history of epilepsy or other neurological condition, a history of major psychiatric disorder, or a history of drug or alcohol problems. Thirty-one neurologically healthy control participants were also recruited. Controls had the additional exclusion criterion that they had never suffered a loss of consciousness from a head injury. The local research ethics committee and hospital ethics committee approved the study and all participants gave informed consent prior to participation, in accordance with the guidelines of the Helsinki Declaration.

TBI participants were recruited from the National Rehabilitation Hospital, Dun Laoghaire, Ireland. The mean age of the TBI group was 28.74 (SD 8.52). This group included 
Table 1. Clinical data for the TBI patients

\begin{tabular}{|c|c|c|c|c|c|}
\hline $\begin{array}{l}\text { TBI } \\
\text { Patient }\end{array}$ & TBI cause & $\begin{array}{c}\text { TBI severity } \\
\text { (PTA) }\end{array}$ & $\begin{array}{c}\text { TBI } \\
\text { severity } \\
\text { (GCS) }\end{array}$ & $\begin{array}{c}\text { Months } \\
\text { since } \\
\text { TBI }\end{array}$ & Location of damage \\
\hline $\mathrm{BE}$ & Assault & Very Severe & 3 & 11 & Left temporal region, cerebellar hemorrhage (CT) \\
\hline OW & RTA-Motorbike & $\mathrm{N} / \mathrm{A}$ & 5 & 23 & Frontal bilaterally, Basal Ganglia, temporal right (CT) \\
\hline $\mathrm{AB}$ & Fall & Extremely Severe & 9 & 31 & Right subdural hematoma, right frontal (CT) \\
\hline DD & RTA-Car & Very Severe & 11 & 34 & Normal $(\mathrm{CT})$ \\
\hline FL & RTA-Car & Extremely Severe & 5 & 38 & $\mathrm{SAH}$, left frontal, left superior temporal, left occipital (CT) \\
\hline $\mathrm{CM}$ & RTA-Motorbike & Extremely Severe & 3 & 38 & Left frontoparietal $(\mathrm{CT})$ \\
\hline ER & Fall & Very Severe & 7 & 21 & Right frontal, SAH (CT) \\
\hline $\mathrm{JC}$ & RTA-Motorbike & Very Severe & 8 & 25 & Left fronto-temporal hematoma $(\mathrm{CT})$ \\
\hline MO & Assault & Very Severe & 13 & 19 & N/A \\
\hline $\mathrm{RB}$ & RTA-Car & Extremely Severe & 7 & 9 & Right frontal, left occipital, DAI (CT) \\
\hline GC & Fall & Very Severe & 3 & 44 & Right frontal $\mathrm{ICH}(\mathrm{CT})$ \\
\hline JC & RTA-Car & Extremely Severe & 12 & 34 & Normal DAI (CT) \\
\hline LM & Assault & Severe & 5 & 76 & Right fronto-parietal, temporal (CT) \\
\hline $\mathrm{RC}$ & RTA-Pedestrian & Extremely Severe & 8 & 29 & SAH, left occipital (CT) \\
\hline $\mathrm{BF}$ & Fall & Extremely Severe & 3 & 13 & $\mathrm{SAH}$, right temporal, left parietal $(\mathrm{CT})$ \\
\hline FM & RTA-Motorbike & Extremely Severe & 7 & 18 & Left frontal, right posterior parietal, temporal, occipital (CT) \\
\hline ER & RTA-Bicycle & Very Severe & 14 & 28 & Right temporal contusions (CT) \\
\hline GM & RTA-Car & Very Severe & $\mathrm{N} / \mathrm{A}$ & 28 & Right fronto-parietal, DAI (CT) \\
\hline $\mathrm{AC}$ & RTA-Car & Extremely Severe & 3 & 32 & Frontal cyst, otherwise normal CT (CT) \\
\hline GL & Fall & Severe & $\mathrm{N} / \mathrm{A}$ & 39 & Right frontal (MRI) \\
\hline DF & RTA-Car & Extremely Severe & $\mathrm{N} / \mathrm{A}$ & $\mathrm{N} / \mathrm{A}$ & N/A \\
\hline PD & Assault & Very Severe & 3 & 53 & Left frontal, left subdural hemorrhage (CT) \\
\hline JG & $\mathrm{N} / \mathrm{A}$ & Severe & $\mathrm{N} / \mathrm{A}$ & $\mathrm{N} / \mathrm{A}$ & N/A \\
\hline CL & RTA-Car & Extremely Severe & 8 & 67 & SAH, right occipital, right hemisphere (CT) \\
\hline $\mathrm{CO}$ & RTA-Car & Extremely Severe & $\mathrm{N} / \mathrm{A}$ & 97 & Bilateral frontal, Left occipital(CT) \\
\hline $\mathrm{GH}$ & RTA-Car & Very Severe & 5 & 28 & Frontal Lobe, SAH, parietal, occipital (CT) \\
\hline JK & Work Accident & Mild & $\mathrm{N} / \mathrm{A}$ & $\mathrm{N} / \mathrm{A}$ & N/A \\
\hline EO & RTA-Car & Very Severe & 4 & 58 & Bilateral frontal, SAH, DAI (CT) \\
\hline DP & RTA-Motorbike & Very Severe & 3 & 9 & Right frontal lobe, Normal CT(CT) \\
\hline GB & RTA-Car & Mild & $\mathrm{N} / \mathrm{A}$ & 84 & DAI (MRI) \\
\hline $\mathrm{JG}$ & RTA-Motorbike & Extremely Severe & 6 & 29 & SAH, bilateral temporal (CT) \\
\hline
\end{tabular}

Note. PTA: sost Traumatic Amnesia (Mild: <1 Hour; Moderate: 1-24 hours; Severe: 1-7 days; Very Severe: 7-28 days; Extremely Severe: $>28$ days); RTA: Road Traffic Accident; DAI: Diffuse Axonal Injury; SAH: Subarachnoid Hemorrhage; ICH: Intracerebral Hemorrhage; N/A: Not Available; CT: Computerized Tomography; MRI: Magnetic Resonance Imaging.

27 men and 4 women. The mean length of time from injury to the time of testing was 36.25 months (SD 22.37). Injury severity was measured by post-traumatic amnesia (PTA) duration and Glasgow Coma Scale (GCS), where available. Clinical data for each TBI participant, where available, are displayed on Table 1. The comparison control group consisted of 24 men and 7 women, selected to match the TBI group on sex, age, and education-level variables. Demographic details of TBI and controls are displayed in Table 2.

\section{MATERIALS AND METHODS}

\section{Screening Tests}

A number of short screening tests for cognitive functioning were administered throughout both sessions. These included: National Adult Reading Test (NART) (Nelson, 1982; Nel- son \& Willison, 1991), Hospital Anxiety and Depression Scale (HADS) (Zigmond \& Snaith, 1983), Frenchay Aphasia Screening Test (FAST) (Enderby et al., 1987), and Frontal Assessment Battery (FAB) (Dubois et al., 2000).

Table 2. Demographic details of TBI and control participants

\begin{tabular}{lcc}
\hline \hline & TBI & Controls \\
\hline $\mathrm{N}$ & 31 & 31 \\
Sex $(\mathrm{m}, \mathrm{fm})$ & 27,4 & 24,7 \\
Age (Years) & 28.74 & 30.23 \\
& $(\mathrm{SD} 8.52)$ & $(\mathrm{SD} \mathrm{14.08)}$ \\
Education Level $^{1}$ & $5 / 10 / 15$ & $5 / 13 / 13$ \\
\hline \hline
\end{tabular}

Note. ${ }^{1}$ Description of education level: $<2$ years education/school-leaving qualification/more than 16 years education. 


\section{Neuropsychological Measures}

Each participant underwent a comprehensive neuropsychological examination that included the following tests. Memory: Subtests (Logical Memory and Digit Span) from the Wechsler Memory Scale-Third Edition (WMS 111) (Wechsler et al., 1998) and a Prospective Memory Task (Walker, 2003). Attention: Subtests from Test of Everyday Attention (Telephone Search and Telephone Search While Counting) (Robertson et al., 1996) and the Sustained Attention to Response Task (Robertson et al., 1997, Manly et al., 2003, Dockree et al., 2006). Participants undertook three tasks of sustained attention: the Fixed SART, Random SART and the DART. During each SART task, for each block, 225 digits were presented (numbers from 1-9) over a 6.3minute period. The participant was instructed to respond with a left mouse press following each digit (go-trials) with the exception of the 25 occasions when the digit 3 (no-go target) appeared. In the Fixed SART, digits were presented sequentially from 1 through 9. In the Random SART, digits were presented in a pseudorandom order. In the DART, a secondary continuous performance task was embedded within the basic design of the Fixed SART, and participants were also required to make a right button press upon detection of grey-colored digits. Executive Functions: Verbal Fluency-FAS test (Spreen \& Benton, 1969; Spreen \& Strauss, 1998); Revised Strategy Application Task (R-SAT) (Levine et al., 2000). Self-Report Measures: Patient Competency Rating Scale (PCRS) (Prigatano \& Altman, 1990), Frontal Systems Behavioral Scale (FrSBe) (Grace \& Malloy, 2002), Cognitive Failures Questionnaire (CFQ) (Broadbent et al., 1982), and Measure of Empathic Tendency (MET) (Mehrabian \& Epstein, 1972).

\section{Awareness Measures}

\section{Metacognitive knowledge}

Awareness Interview-adapted (Anderson \& Tranel, 1989). The standard interview was administered prior to each participant's neuropsychological evaluation. The standardized procedure comprised 8 sections, consisting of questions regarding diagnosis/reason for hospitalization, if any, thinking, orientation, memory, attention, speech and language, activities of daily living (ADLs), and overall impression as to how they felt they had performed on the tests and ability to continue with/return to work, education or hobbies. Scoring was carried out in 3 stages, culminating in an "Awareness Index" as described in Anderson \& Tranel (1989). This led to the deviation scores ranging from 0-2 for each item [Reason for Hospitalization (if any), thinking, orientation, memory, attention, language, activities of daily living, overall performance, and ability to return to work]. The eight deviation scores were then added together to get a total deviation score, the "Awareness Index," ranging from 0 (indicating no discrepancy between participant's selfreport and neuropsychological performance) to 16 (indicat- ing maximum discrepancy between participant's selfreport and neuropsychological performance).

\section{Discrepancy Scores on Questionnaires Self and Other}

Three questionnaires were rated for identical items by participants and a significant other, caregiver, or friend. These were the Patient Competency Rating Scale (PCRS) (Prigatano et al., 1986), the Frontal Systems Behavioral Scale (FrSBe) (Grace \& Malloy, 2002), and the Cognitive Failures Questionnaire (CFQ) (Broadbent et al., 1982). Discrepancy between self-ratings and significant other ratings were used as indicators of inaccurate perception of functional competencies and cognitive, behavioral, and social abilities.

\section{Online Emergent Awareness}

\section{Error-monitoring}

Error-monitoring on Fixed SART, Random SART and DART (McAvinue et al., 2005; O'Keeffe et al., 2004). As participants performed the three conditions of the SART, error awareness was measured by asking participants to verbally indicate their awareness of making an error by saying the word "hit" following an error of commission on the no-go target, the number 3 . The proportion of aware errors over the total number of errors made gave the overall error awareness score on the SART.

\section{Online anticipatory awareness}

Prediction Tasks: Discrepancy between predicted and actual performance in cognitive tasks (Fischer et al., 2004a). Accuracy of prediction on cognitive tasks was assessed using WMS Digit Span (Forwards) and Verbal Fluency (FAS). Participants were asked prior to performing each of these tasks to predict how many numbers they would immediately recall (Digit Span) or words they could come up with in one minute beginning with a certain letter (Verbal Fluency). Prediction accuracy was assessed in each task by calculating an average score [(Prediction minus Performance)/Prediction $\times 100$ ].

\section{RESULTS}

\section{Demographic Data}

Demographic data for all TBI patients and control participants are detailed in Table 2. Groups did not differ significantly in terms of age $[t=-.502, d f=60, p>.05]$, sex $\left[\chi^{2}=.995, d f=1, p>.05\right]$ or education level $\left[\chi^{2}=.625\right.$, $d f=2, p>.05]$. 


\section{Do TBI Participants Differ from Control Participants Overall on Awareness Measures?}

\section{TBI versus control group comparisons}

Composite scores for metacognitive knowledge (Awareness Index, PCRS discrepancy score, FrSBe discrepancy score and CFQ discrepancy score), online emergent awareness (Overall Error Awareness on Fixed SART, Random SART, and DART) and online anticipatory awareness (Overall Prediction Tasks Accuracy on Digit Span and Verbal Fluency) were calculated based on $z$-scores from each of the individual awareness measures. A composite score of Overall Awareness, including $z$-scores from the metacognitive knowledge tests, online emergent awareness and online anticipatory awareness were calculated [ $z$-scores of all awareness measures: awareness interview, discrepancy scores on PCRS, FrSBe, CFQ, online monitoring on SART and prediction tasks].

An independent-samples $t$-test revealed that TBIs scored significantly worse than controls on Overall Awareness Composite score $[t(53.9)=-2.870 p<.01]$. The Overall Awareness Composite Scores for TBI and control participants are depicted later in Figure 1.

To investigate performance across the different awareness measures, a mixed ANOVA was run. The betweensubjects factor was group (two levels: TBI and control) and the within-subjects factor was awareness type (3 levels: metacognitive knowledge, online emergent awareness, online anticipatory awareness). There was a significant main effect of group $[F(1,57)=8.903, p<.01]$, indicating that TBI participants were significantly impaired across each of the three awareness measures compared to controls. The main

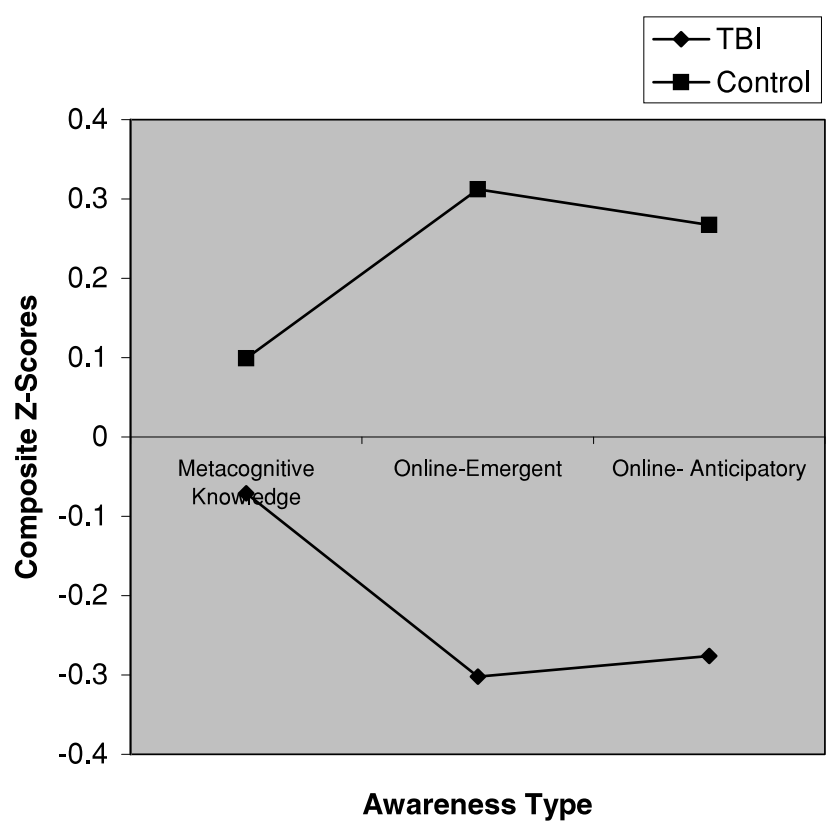

Fig. 1. Awareness type by group for TBI and control participants. effect for awareness type $[F(2,114)=0.10, p>.05]$ and the interaction effect between awareness type and group $[F(4,114)=1.576, p>.05]$ did not reach significance. Figure 1, later, depicts awareness type by group for TBIs and control participants.

\section{What is the Relationship of Awareness Composite Scores to Other Measures for TBI Participants?}

Table 3 shows selected correlations between each category of composite awareness and other measures of cognitive function.

\section{Metacognitive knowledge}

Higher Metacognitive Knowledge in TBI participants was associated with less impaired scores on total frontal behavior as rated by significant others on the FrSBe, specifically with less impairment on disinhibition and executive dysfunction symptoms. Higher metacognitive knowledge also seemed to be associated with higher total competency as rated by significant others and specifically on activities of daily living and interpersonal subscales. Though it did not reach significance level, there was a trend towards higher metacognitive knowledge being associated with higher HADS depression ( $p=.059)$.

\section{Online-emergent awareness}

Higher levels of online-emergent awareness were associated with lower levels of HADS Anxiety. Higher levels of online-emergent awareness were also associated with lower levels of impairment of frontal behavior, on total FrSBe and each subscale. Higher online-emergent awareness was associated with higher ratings of competency as rated by significant others on PCRS Total and specifically on the interpersonal subscale. Fewer errors of commission on the

Table 3. Pearson product-moment correlations between awareness category and selected measures for TBI participants

\begin{tabular}{lccc}
\hline \hline Variable & $\begin{array}{c}\text { Metacognitive } \\
\text { Knowledge }\end{array}$ & $\begin{array}{c}\text { Online- } \\
\text { Emergent } \\
\text { Awareness }\end{array}$ & $\begin{array}{c}\text { Online- } \\
\text { Anticipatory } \\
\text { Awareness }\end{array}$ \\
\hline HADS Anxiety & .009 & $-.501 * *$ & -.239 \\
HADS Depression & .349 & -.242 & .036 \\
FrSBe Total (Other-rated) & $-.379 *$ & $-.429 *$ & .025 \\
FrSBe Apathy & -.115 & $-.412^{*}$ & -.153 \\
FrSBe Disinhibition & $-.460^{*}$ & $-.392^{*}$ & .059 \\
FrSBe Executive Dysfunction & $-.421^{*}$ & $-.370^{*}$ & .145 \\
PCRS (Other-rated) & $.443 *$ & $.394 *$ & -.121 \\
PCRS ADL & $.490 * *$ & .378 & -.271 \\
PCRS Interpersonal & $.419 *$ & $.491 * *$ & -.148 \\
Fixed SART Errors & .219 & $-.474 *$ & -.046 \\
DART Errors of Commission & -.113 & -.242 & $-.422 *$ \\
\hline \hline
\end{tabular}

Note. $*$ Significant at $p<.05$.

$* *$ Significant at $p<.01$. 
Fixed SART were also associated with higher levels of online-emergent awareness.

\section{Online-anticipatory awareness}

Higher levels of online-anticipatory awareness were associated with lower errors of commission on the DART. There were no other significant correlations with the awareness measures with any other demographic or neuropsychological variable for TBI participants.

\section{What is the Relationship of the Three Awareness Measures to Each Other?}

In order to examine the relationship between the three different types of awareness measures, correlational analyses were conducted. Metacognitive knowledge was not associated with either online-emergent $[r=.184, p>.05]$ or online-anticipatory awareness $[r=.009, p>.05]$. A strong association between online-emergent and online-anticipatory awareness was evident $[r=.717, p<.0001]$.

\section{Do TBI Participants with High and Low Awareness groups differ across awareness measures? TBI High Awareness versus TBI Low Awareness versus Control Comparison by Awareness Type}

Following an exploration of raw awareness scores of the TBI data, it became clear that the TBI participant group was not normally distributed across several tests. The TBI group was therefore divided into a high self-awareness (TBI High SA) group and a low self-awareness group (TBI Low SA), based on a median split of the composite overall awareness score. Further analysis of the awareness types was thus performed on 16 TBI High SA, 15 TBI Low SA, and 31 controls. These groups did not differ in terms of age $[F(2,59)=0.683, p>.05], \operatorname{sex}\left[\chi^{2}=1.769, d f=2, p>\right.$ $.05]$, or education level [ $\left.\chi^{2}=0.66, d f=4, p>.05\right]$. Table 4 displays clinical data for TBI High SA and TBI Low SA

Table 4. Clinical Data for TBI High SA and TBI Low SA groups

\begin{tabular}{lcc}
\hline \hline & TBI High SA & TBI Low SA \\
\hline Time since injury (Months) & 34.44 (SD 21.3) & 38.67 (SD 24.5) \\
Severity of injury (PTA): & 4.00 (SD 1.1) & 4.27 (SD 1.1) \\
Severity of injury (GCS): & 6.23 (SD 4.2) & 6.73 (SD 2.3) \\
Neuroradiological data ${ }^{1}:$ & & 4 \\
$\quad$ Right frontal & 6 & 3 \\
$\quad$ Left frontal & 3 & 4 \\
Bifrontal & 3 & 4 \\
$\quad$ Diffuse axonal & & 4 \\
$\quad$ Injury/unspecified & 4 & 4 \\
\hline \hline
\end{tabular}

Note. Statistical analysis $\left(\chi^{2}\right)$ could not be performed on neuroradiological data because of cells not reaching minimum expected frequency. groups. TBI High SA and TBI Low SA groups did not differ in terms of Time Since Injury $[t(26)=-.488, p>.05]$ or severity of injury, as measured by PTA $\left[U=-1.010, n_{1}=\right.$ $\left.15, n_{2}=15, p>.05\right]$ or $\operatorname{GCS}\left[U=-1.031, n_{1}=13, n_{2}=\right.$ $11, p>.05]$.

In order to investigate performance across the different awareness measures, a mixed ANOVA was run. The betweensubjects factor was group (3 levels: TBI High SA, TBI Low $\mathrm{SA}$, and control) and the within-subjects factor was awareness type (3 levels: metacognitive knowledge, online emergent awareness, online anticipatory awareness). There was a significant main effect of group $[F(1,56)=29.515, p<$ $.0001]$, and a significant interaction between awareness type and group $[F(4,112)=2.866]$. The main effect for awareness type did not reach significance $[F(2,112)=.443]$.

Post hoc $t$-tests (independent and paired-samples) indicated that TBI Low SA had significantly lower metacognitive knowledge composite score compared to both TBI High SA $[t(28)=-2.868, p<.01]$ and controls $[t(18.698)=-2.577, p<.05]$. TBI Low SA had significantly lower online-emergent composite scores than TBI High SA $[t(17.827)=-6.597, p<.001]$ and controls $[t(43)=-5.935, p<.001]$, and significantly lower onlineanticipatory composite scores than both TBI High SA $[t(28)=-2.771, p<.01]$ and controls $[t(44)=-3.022$, $p<.01]$. TBI High SA and controls did not differ significantly on metacognitive knowledge $[t(19.357)=1.129$, $p>.05]$, online-emergent $[t(43.983)=1.467, p>.05]$, or online-anticipatory $[t(44)=-.484, p>.05]$. These post hoc tests also indicated that TBI Low SA performed significantly worse on online-emergent than online-anticipatory $[t(14)=2.271, p<.05]$. Figure 2, later, depicts this interaction with the three groups and three awareness types.

\section{Do TBI High and Low Awareness Groups Differ Across Neuropsychological Measures and Behavioral Rating Scales?}

In order to investigate whether the TBI High SA and TBI Low SA groups differed across performance on neuropsychological tests, a series of one-way ANOVAs were run, with Group (TBI High SA, TBI Low SA and controls) as between-subjects factor and each neuropsychological test as the dependent variable. Table 5 displays the mean scores and standard deviations for each test. $F$-values and $p$-values are also displayed, as are post-hoc Bonferroni comparisons to indicate where differences lie. As can be seen from Table 5, TBI High SA and TBI Low SA groups do not differ significantly from each other on any of the neuropsychological measures.

Table 6 displays the mean scores and standard deviations for other-rated PCRS and FrSBe behavior rating scales. Oneway between-subjects' ANOVAs were conducted in order to establish group differences in mean scores PCRS otherrated scale (total and subscales). $F$ values and post hoc Bonferroni comparisons are also displayed in Table 6. As can be seen from Table 6, TBI Low SA are rated signifi- 


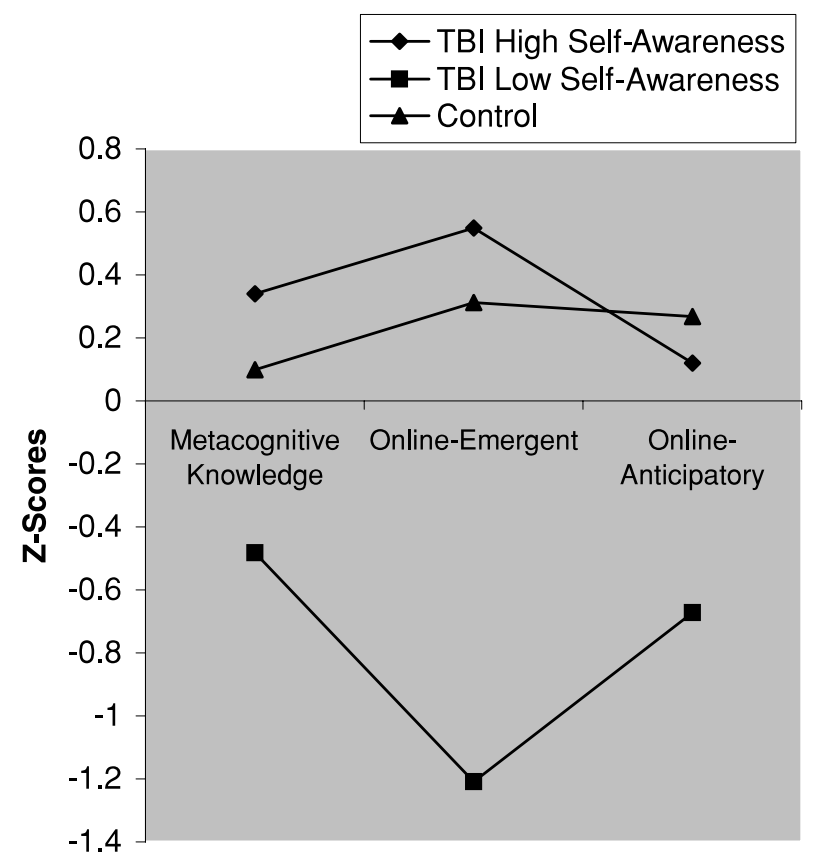

Awareness Type

Fig. 2. Interaction between TBI High SA, TBI Low SA and Control Group on three composite awareness scores. cantly lower on competency total and subscales by significant others (SOs) compared to TBI High SA on total competency, activities of daily living, and interpersonal relationships scales. Also, SO ratings for frontal systems dysfunction for TBI Low SA are also significantly higher than controls. Furthermore, SO ratings for TBI Low SA are significantly higher than TBI High SA for disinhibition subscale.

\section{DISCUSSION}

This study used a multidimensional approach to comprehensively assess awareness in traumatic brain injury participants and matched healthy controls. The TBI group as a whole, demonstrated impaired awareness on metacognitive knowledge, online-emergent awareness, and onlineanticipatory awareness, compared to controls. Furthermore, significant relationships were found between executive dysfunction symptoms and interpersonal difficulties and overall metacognitive knowledge and online emergent awareness. Sustained attention abilities were associated with online emergent awareness and online anticipatory awareness. Measures of metacognitive knowledge did not correlate with the other two types of awareness. Both types of online awareness, emergent and anticipatory, showed a strong relation-

Table 5. Neuropsychological Test Scores for each participant group: TBI High SA and TBI Low SA Do Not Differ on any Standard Neuropsychological measure

\begin{tabular}{|c|c|c|c|c|c|c|}
\hline $\begin{array}{l}\text { Cognitive } \\
\text { Functions }\end{array}$ & Cognitive Tests & $\begin{array}{l}\text { TBI Low SA } \\
\quad(n=15)\end{array}$ & $\begin{array}{l}\text { TBI High SA } \\
\quad(n=16)\end{array}$ & $\begin{array}{l}\text { Controls } \\
(n=31)\end{array}$ & $\begin{array}{c}\mathrm{F} \\
\text { Value }\end{array}$ & $\begin{array}{c}P \\
\text { Value }\end{array}$ \\
\hline Screening Tests & NART Estimated IQ & $99.54(10.1)^{\mathrm{a}}$ & $107.20(11.7)$ & $113.58(8.4)^{\mathrm{a}}$ & 9.969 & $<.001$ \\
\hline \multirow{5}{*}{ Mean (SD) } & HADS-Anxiety & $11.0(4.6)^{\mathrm{a}}$ & $8.31 \quad(4.6)$ & $6.29(3.5)^{\mathrm{a}}$ & 6.934 & $<.01$ \\
\hline & HADS-Depression & $8.13(4.9)^{\mathrm{a}}$ & $7.75(4.4)^{\mathrm{b}}$ & $2.35(1.8)^{\mathrm{ab}}$ & 19.398 & $<.001$ \\
\hline & FAST-Aphasia & $28.14 \quad(1.3)$ & $28.00(2.8)^{\mathrm{b}}$ & $29.29(0.8)^{\mathrm{b}}$ & 4.389 & $<.05$ \\
\hline & WMS Orientation & $12.29(1.2)^{\mathrm{a}}$ & $12.80 \quad(0.9)$ & $13.29(0.7)^{\mathrm{a}}$ & 6.30 & $<.01$ \\
\hline & MET & $18.27(34.5)$ & $18.56(34.5)$ & $37.87(18.4)$ & 3.774 & $<.05$ \\
\hline Memory & WMS Logical Memory I & $36.2(11.2)^{\mathrm{a}}$ & $40.93(10.1)^{b}$ & $53.03(10.5)^{\mathrm{ab}}$ & 13.694 & $<.001$ \\
\hline \multirow[t]{3}{*}{ Mean (SD) } & WMS Logical Memory II & $21.27(9.9)^{\mathrm{a}}$ & $23.21(10.1)^{b}$ & $32.06(8.2)^{\mathrm{ab}}$ & 8.947 & $<.001$ \\
\hline & WMS Digit Span Forward & $10.13(2.0)^{\mathrm{a}}$ & $11.4(2.3)^{b}$ & $13.19(1.6)^{\mathrm{ab}}$ & 14.05 & $<.001$ \\
\hline & Prospective Memory Test & $2.73(2.7)^{\mathrm{a}}$ & $2.64(2.7)^{\mathrm{b}}$ & $5.23(1.4)^{\mathrm{ab}}$ & 9.734 & $<.001$ \\
\hline Attention & TEA-A & $4.41(1.6)^{\mathrm{a}}$ & $3.52(0.9)$ & $3.03(0.9)^{\mathrm{a}}$ & 7.451 & $<.001$ \\
\hline \multirow[t]{5}{*}{ Mean (SD) } & TEA-B & $6.55(2.9)^{\mathrm{a}}$ & $6.17 \quad(0.8)$ & $4.27(2.0)^{\mathrm{a}}$ & 4.780 & $<.05$ \\
\hline & TEA-Dual Task Decrement & $2.16 \quad(2.6)$ & $2.55(3.4)$ & $1.26(1.5)$ & 1.745 & n.s. \\
\hline & $\mathrm{SART}_{\text {fixed }}$ Mean Errors of Commission & $2.43(2.8)^{\mathrm{a}}$ & $1.8 \quad(0.9)$ & $0.94(0.9)^{\mathrm{a}}$ & 4.719 & $<.05$ \\
\hline & SART $_{\text {random }}$ Mean Errors of Commission & $8.61(3.6)^{\mathrm{a}}$ & $6.14(4.8)^{b}$ & $2.21(2.4)^{\mathrm{ab}}$ & 16.351 & $<.001$ \\
\hline & DART Mean Errors of Commission & $6.5(4.3)^{\mathrm{a}}$ & $3.96(2.4)$ & $2.27(1.6)^{\mathrm{a}}$ & 12.066 & $<.001$ \\
\hline Executive & R-SAT Proportion & $0.736(0.1)$ & $0.738(0.1)$ & $0.844(0.2)$ & 3.713 & $<.05$ \\
\hline Functions & Verbal Fluency FAS (Total) & $31.2(9.1)^{\mathrm{a}}$ & $36.0(10.2)^{b}$ & $50.74(13.8)^{\mathrm{ab}}$ & 16.26 & $<.001$ \\
\hline Mean (SD) & FAB & $15.13(1.9)^{\mathrm{a}}$ & $16.2 \quad(1.9)$ & $17.23(1.1)^{\mathrm{a}}$ & 9.084 & $<.001$ \\
\hline
\end{tabular}

Note. NART $=$ National Adult Reading Test Estimated Pre-Morbid Performance IQ; HADS = Hospital Anxiety and Depression Scale; FAST $=$ Frenchay Aphasia Screening Test; WMS = Wechsler Memory Scale; MET = Measure of Empathic Tendency; TEA = Test of Everyday Attention; SART = Sustained Attention to Response Task; DART = Dual-Task Attention To Response Task; R-SAT = Revised Strategy Application Task; FAB = Frontal Assessment Battery; Post-hoc significant comparisons are indicated by the following symbols: a: Post hoc Bonferroni comparison $(P<.05)$ : TBI Low SA versus Controls; b: Post hoc Bonferroni comparison $(P<.05)$ : TBI High SA versus controls. 
Table 6. Patient Competency Rating Scale (Other-Rated) and Frontal Systems Behavioral Scale (Total and Subscales) Mean scores and SD for each group: TBI Low SA are rated as more disinhibited, less competent, less interpersonally able than TBI High SA group

\begin{tabular}{|c|c|c|c|c|}
\hline $\begin{array}{l}\text { PCRS } \\
\text { Mean (SD) }\end{array}$ & $\begin{array}{c}\text { TBI } \\
\text { Low SA }\end{array}$ & $\begin{array}{c}\text { TBI } \\
\text { High SA }\end{array}$ & Controls & $\begin{array}{c}F \\
\text { Value }\end{array}$ \\
\hline \multicolumn{5}{|c|}{ PCRS (Other Rated) } \\
\hline Total & $106.36(26.4)^{\mathrm{ac}}$ & $123.93(19.0)^{\mathrm{c}}$ & $133.38(9.7)^{\mathrm{a}}$ & $11.325 * *$ \\
\hline ADL Other-rated & $31.0 \quad(6.7)^{\mathrm{ac}}$ & $35.73(4.5)^{\mathrm{c}}$ & $37.33(2.7)^{\mathrm{a}}$ & $7.505^{* *}$ \\
\hline Cognitive Other-rated & $28.08(8.2)^{\mathrm{a}}$ & $32.06 \quad(6.3)$ & $36.24(2.8)^{\mathrm{a}}$ & $8.081 * *$ \\
\hline Interpersonal Other-rated & $23.58(5.1)^{\mathrm{ac}}$ & $29.46(4.5)^{\mathrm{c}}$ & $30.90(3.6)^{\mathrm{a}}$ & $11.565 * *$ \\
\hline Emotional Other-rated & $23.16(6.0)^{\mathrm{a}}$ & $26.67 \quad(5.6)$ & $28.14(3.3)^{\mathrm{a}}$ & $3.972 *$ \\
\hline \multicolumn{5}{|c|}{ FrSBe (Other Rated) } \\
\hline Total & $121.64(40.9)^{\mathrm{a}}$ & $98.33(24.7)$ & $79.93(19.8)^{\mathrm{a}}$ & $11.068 * *$ \\
\hline Apathy & $34.14(13.4)^{\mathrm{a}}$ & $30.07 \quad(7.1)$ & $24.31(7.6)^{\mathrm{a}}$ & $5.814 * *$ \\
\hline Disinhibition & $37.79(14.2)^{\mathrm{ac}}$ & $228.0 \quad(8.1)^{\mathrm{c}}$ & $25.41 \quad(6.4)^{\mathrm{a}}$ & $8.625^{* *}$ \\
\hline Executive Dysfunction & $49.0(16.4)^{\mathrm{a}}$ & $40.27(12.4)^{\mathrm{b}}$ & $30.97(8.2)^{\mathrm{ab}}$ & $11.684 * *$ \\
\hline
\end{tabular}

Note. $*$ Significant at $p<.05$ level.

$* *$ Significant at $p<.01$ level.

${ }^{a}$ Post hoc Bonferroni comparison $(P<.05)$ : TBI Low SA versus controls.

${ }^{\mathrm{b}}$ Post hoc Bonferroni comparison $(P<.05)$ : TBI High SA versus controls.

${ }^{\mathrm{c}}$ Post hoc Bonferroni comparison $(P<.05)$ : TBI Low SA versus TBI High SA.

ship with each other. TBI participants with high selfawareness performed equally as well as controls. Directly in contrast to this, the TBI low self-awareness group was significantly impaired on every measure of awareness. The TBI High SA group and the TBI Low SA group did not differ from each other in terms of severity, time since injury, or any neuropsychological test. However, the TBI Low SA group were rated as demonstrating poorer interpersonal skills, more symptoms of disinhibition, less competency in activities of daily living and less overall competency than the TBI High SA group, as rated by significant others on the FrSBe and PCRS.

The TBI High SA and TBI Low SA patient groups did not differ significantly from each other in severity of injury, chronicity, or on any test on the extensive neuropsychological test battery, which may be somewhat surprising considering the distinctively different performances of the two patient groups across each of the three categories of awareness and the many specific tests. The TBI Low SA group showed a significantly poorer neuropsychological profile compared to controls than the TBI High SA group did, in that the TBI Low SA group were significantly impaired across almost all of the neuropsychological battery of tests compared to controls. This is in contrast to the TBI High SA group, who despite showing significant impairment on the memory tests and higher HADS depression ratings, performed well on the test battery overall and did not differ significantly from controls on the attention tests, with the exception of the random SART or the executive function tests. However, considering the rating scales, the TBI Low SA group were rated as being more impaired on total competence ratings than the TBI High SA group, as rated by their SO on the PCRS scale. The TBI Low SA group was also rated as significantly less competent on activities of daily living and interpersonal abilities on the PCRS and more disinhibited on the FrSBe.

These findings are only partially consistent with previous studies that divided their TBI participants by awareness group. Noe et al. (2005) showed no significant differences in terms of chronicity, GCS, or length of coma between TBI High and Low SA groups. They did show that the TBI Low SA group had a significantly longer PTA than the High SA group, a finding that was not replicated in this study. Prigatano and Altman (1990) also did not find any significant differences in severity (as measured by GCS scores) and chronicity between their three groups of TBI (overestimators, accurate, and underestimators). In terms of neuropsychological performance differences, the findings from this study are partially consistent with Prigatano and Altman (1990) and Prigatano et al. (1997), who did not find any relationship between awareness group membership and neuropsychological measurements. Speed of finger tapping for the left hand was found to be the only discriminatory measure between groups. Hoofien et al. (2004) also showed no significant difference across memory and attention domains but TBI patients who overestimated were significantly worse on comprehension and showed generally worse behavioral outcome as measured by the behavior evaluation checklist, examining the frequency of behavioral disturbances, including impulsivity and aggressiveness. The TBI patients who overestimated their abilities also showed a worse psychiatric outcome than those with accurate estimates of their functioning and underestimators.

Hoofien et al.'s (2004) findings are particularly relevant to this study, because the family members of the overestimators attributed significantly more behavioral distur- 
bances to those in this awareness group than the family members of those patients who were accurate or underestimated. This is consistent with the findings in this study that show that TBI Low SA group were rated as showing significantly more disinhibition and interpersonal problems than those with High SA. It has been said that standard neuropsychological measures may fail to capture the more complex neuropsychological impairments when TBI patients are divided in terms of disturbances in self-awareness (Prigatano \& Schacter, 1991), a suggestion that this study would support. Noe et al. (2005) did show numerous differences between the High SA group and Low SA group in their study however, in terms of neuropsychiatric and neuropsychological profile. Despite numerous neuropsychological differences in their study however, only one task of executive function (WCST number of categories) and delayed recall (Tavec Free delayed recall) were independent predictors of self-awareness in the groups.

Other studies have found similar results to Noe et al. (2005) showing that certain measures of executive function and memory predict awareness (McAvinue et al., 2005; Ownsworth et al., 2002; Trudel et al., 1998). The present study only partially replicated some of these findings by showing an association between sustained attention and onlineemergent awareness and online-anticipatory awareness. The ability to maintain alertness in the context of routine tasks appears to predict the ability to monitor ongoing performance while performing a task but also in relation to predicting future performances. Greater metacognitive knowledge was predicted by greater total competence and interpersonal abilities, and competence on ADLs. Similarly, the more symptoms of executive dysfunction, disinhibition, and frontal symptoms in general displayed, the more likely a TBI patient was to be impaired on metacognitive knowledge. The total ratings of general frontal symptoms and each of the subscales of apathy, disinhibition and executive dysfunction, as well as the total competency ratings and the interpersonal subscale predicted levels of online emergent awareness also. These findings show that executive deficits and difficulties in the control of behavior are intrinsically related to awareness deficits. No relationships were found to associate memory and awareness, despite some previous findings showing this association (Noe et al., 2005; Trudel et al., 1998).

The findings that metacognitive knowledge did not correlate with the two types of online measures (Emergent and Anticipatory), whereas both online emergent and onlineanticipatory awareness measures strongly correlate with one another $(r=.717)$, support Toglia and Kirk's categorization of awareness into metacognitive knowledge versus online awareness (Toglia \& Kirk, 2000). The data from this study also provide further evidence for the neurocognitive factors involved in the DICE and CAM theories of awareness differentiating global awareness and online monitoring (Ownsworth et al., In Press; Schacter, 1990). The associations found in this study between the awareness measures and symptoms of frontal behavior implicate the fron- tal lobes in each type of awareness, metacogntive knowledge and online monitoring, as proposed by the aforementioned models and the hierarchy of brain function model (Stuss et al., 2001). As is evident from the neuroradiological data of the TBI patients in the present study, discrete lesion location is unusual in the context of traumatic brain injury. Sherer et al. (2005) indicated that it may be more likely that broadly distributed networks may be disrupted to cause impairments in self-awareness, than any specific lesion location. Because DAI in TBI is associated with frontal, prefrontal, and cingulate hypoperfusion and damage to the subcortical areas (Boone et al., 1999; Fontaine et al., 1999), it would seem likely that frontal networks, including their subcortical projections, are involved in self-awareness. The recent fMRI study by Schmitz et al. (2006) provides support for this, indicating that the medial pre-frontal and retrosplenial cortical regions play a primary role in self-referential evaluative processes and that activation of the right anterior dorsolateral prefrontal cortex was associated with reduced accuracy on the PCRS.

The emotional impact of either self-awareness has been investigated in a number of previous studies. Greater awareness has frequently, though not exclusively, been linked with poorer emotional adjustment or greater distress (Sawchyn et al., 2005; Sohlberg et al., 1998). However, in this study, there was no significant difference between depression and anxiety scores for the High and Low SA groups, with the High SA group showing slightly lower, though non-significant, ratings. Both patient groups showed significantly greater depression levels than controls and only the Low SA group differed significantly from controls for anxiety levels. Indeed, there was a moderate association between anxiety levels and online-emergent awareness, in the opposite direction to that found in previous studies. TBI participants who were better able to monitor their errors scored lower on anxiety levels. Noe et al. (2005) also showed no difference between High and Low SA groups on depression and anxiety scales. However, as mentioned earlier, the Low SA group in the Noe study nevertheless showed greater neuropsychiatric symptoms as measured by the neuropscyhiatric inventory. Wallace and Bogner (2000) also found that whereas many TBI patients reported mild or greater depression and anxiety, it was not associated with awareness ratings. Ownsworth and Fleming (2005) found that intellectual awareness (Metacognitive Knowledge) was not associated with better or worse emotional adjustment, but that higher levels of hope for the future was related to better online-awareness. These authors also point out that the association between greater emotional distress and higher levels of awareness found in some previous studies may be related to earlier stages of recovery. Consistent with this, the TBI participants in the present study were, on average, three years post injury. However, there was a non-significant trend towards significance in the association between metacognitive knowledge and depression levels in the present study. The association between emotional adjustment and awareness 
type is certainly an area that deserves further research, particularly in relation to stage of recovery.

In relation to methodological considerations of this study, it is likely that making the awareness response ("hit") to assess emergent awareness will produce a switch cost. The primary concern was to assess emergent awareness using a straightforward verbal response. It was reasoned that simply asking participants to respond in a different modality (a verbal as opposed to motor response) would cause less interference with ongoing task performance than a secondary motor response. Moreover, aware responses were accepted up to three trials following a commission error so that the task demands and/or slowed reaction times of the TBI participants would be less likely to compromise the likelihood of emergent awareness. Furthermore, in a related study, a switch cost was observed on the dual-task version of the SART in which the dual-task element, rather than making a verbal response, was to respond with a different key press to a grey digit. In that study, the dual-task switch cost was equal for TBI participants and controls (Dockree et al., 2006). We therefore feel that although switch costs will exist in tasks with dual-task elements, these switch costs do not interfere with the primary aim of assessing emergent awareness.

In conclusion, this study has shown that awareness of deficits almost certainly cannot be either described or measured using a single, unidimensional approach to assessment. It has confirmed the multidimensional, complex nature of awareness and is one of the first studies that comprehensively examines awareness across the three levels of awareness, as outlined by clinical models suggested by Crosson et al. (1989) and Toglia and Kirk (2000). In a recent review by Prigatano (2005), certain "Facts" about impaired awareness after TBI were described. For example, findings that relate severity of injury and emotional distress to awareness, and the assumption that physical deficits are more readily acknowledged by TBI patients than emotional/ interpersonal (Fischer et al., 2004b). These facts need to be considered carefully with regards to the "object of insight" that was used to assess impaired awareness (Markova \& Berrios, 2001), as a huge number of studies have only used one single measure to assess awareness in TBI clinical groups, typically a discrepancy score on one questionnaire. It is clear from the present findings that behavior suggesting executive dysfunction and complex social and interpersonal difficulties are related to each type of awareness. However, standard neuropsychological assessments may not reflect these underlying associations, as this study demonstrated. The association between sustained attention, onlineemergent awareness and online-anticipatory awareness may suggest a possible route for rehabilitation, because it has been shown in a study using similar methodology to the present one that the provision of auditory feedback on error led to an improvement in sustained attention performance on the SART for TBI participants. Although it was unclear whether feedback on error enhanced error awareness or general arousal, the possibility that feedback on error may improve online error-monitoring certainly merits further investigation (McAvinue et al., 2005). Despite the small patient sample size $(n=31)$ in the present study, the distinct lack of association between the composite scores of metacognitive knowledge and the two online-awareness types, strongly suggests that previous studies may not have examined the whole, multifaceted picture of awareness of deficits following TBI. This study has taken us a step closer to understanding the complex phenomenon that is awareness of deficits.

\section{ACKNOWLEDGMENTS}

The authors thank all the participants under the care of the National Rehabilitation Hospital, Dun Laoghaire, Co. Dublin. This work was supported by a Government of Ireland Scholarship administered by the Irish Research Council for Humanities and Social Sciences to Fiadhnait O'Keeffe and by the Irish Higher Education Authority's Program for Research in Third-Level Institutions (8AA. G03007) to Professor Ian H. Robertson. No financial relationships exist that could be interpreted as a conflict of interest affecting this manuscript. The information in this manuscript is new and original and has never been published either electronically or in print.

\section{REFERENCES}

Abreu, B.C., Seale, G., Scheibel, R.S., Huddleston, N., Zhang, L., \& Ottenbacher, K.J. (2001). Levels of self-awareness after acute brain injury: How patients' and rehabilitation specialists' perceptions compare. Archives of Physical Medicine and Rehabilitation, 82, 49-56.

Allen, C.C. \& Ruff, R.M. (1990). Self-rating versus neuropsychological performance of moderate versus severe head-injured patients. Brain Injury, 4, 7-17.

Anderson, S.W. \& Tranel, D. (1989). Awareness of Disease States following cerebral infarction, dementia, and head trauma: Standardized assessment. The Clinical Neuropsychologist, 3, 327-339.

Bogod, N.M., Mateer, C.A., \& MacDonald, S.W. (2003). Selfawareness after traumatic brain injury: A comparison of measures and their relationship to executive functions. Journal of the International Neuropsychological Society, 9, 450-458.

Boone, K.B., Miller, B.L., Lee, A., Berman, N., Sherman, D., \& Stuss, D.T. (1999). Neuropsychological patterns in right versus left frontotemporal dementia. Journal of the International Neuropsychological Society, 5, 616-622.

Broadbent, D.E., Cooper, P.F., FitzGerald, P., \& Parkes, K.R. (1982). The Cognitive Failures Questionnaire (CFQ) and its correlates. British Journal of Clinical Psychology, 21, 1-16.

Coben, R.A., Boksenbaum, S.I., \& Kulberg, A.M. (1995). Cognitive determinants of unawareness of deficits: The importance of specific frontal-mediated executive functions. Archives of Clinical Neuropsychology, 10, 309-310.

Crosson, C., Barco, P.P., Velozo, C., Bolesta, M.M., Cooper, P.V., Werts, D., \& Brobeck, T.C. (1989). Awareness and Compensation in postacute head injury rehabilitation. Journal of Head Trauma Rehabilitation, 4, 46-54.

Dockree, P.M., Bellgrove, M.A., O'Keeffe, F., Moloney, P., Aimola, L., Carton, S., \& Robertson, I.H. (2006). Sustained Attention 
in traumatic brain injury (TBI) and healthy controls: Enhanced sensitivity with dual-task load. Experimental Brain Research, $168,218-229$.

Dubois, B., Slachevsky, A., Litvan, I., \& Pillon, B. (2000). The FAB: A Frontal Assessment Battery at bedside. Neurology, 55, 1621-1626.

Enderby, P.M., Wood, V.A., Wade, D.T., \& Hewer, R.L. (1987). The Frenchay Aphasia Screening Test: A short, simple test for aphasia appropriate for non-specialists. International Rehabilitation Medicine, 8, 166-170.

Fischer, S., Gauggel, S., \& Trexler, L.E. (2004a). Awareness of activity limitations, goal setting and rehabilitation outcome in patients with brain injuries. Brain Injury, 18, 547-562.

Fischer, S., Trexler, L.E., \& Gauggel, S. (2004b). Awareness of activity limitations and prediction of performance in patients with brain injuries and orthopedic disorders. Journal of the International Neuropsychological Society, 10, 190-199.

Fleming, J. \& Strong, J. (1999). A longitudinal study of selfawareness: Functional deficits underestimated by persons with brain injury. The Occupational Therapy Journal of Research, 19, 3-17.

Fleming, J.M., Strong, J., \& Ashton, R. (1996). Self-awareness of deficits in adults with traumatic brain injury: How best to measure? Brain Injury, 10, 1-15.

Fontaine, A., Azouvi, P., Remy, P., Bussel, B., \& Samson, Y. (1999). Functional anatomy of neuropsychological deficits after severe traumatic brain injury. Neurology, 53, 1963-1968.

Gauggel, S., Hoop, M., \& Werner, K. (2002). Assigned versus self-set goals and their impact on the performance of braindamaged patients. Journal of Clinical \& Experimental Neuropsychology, 24, 1070-1080.

Grace, J. \& Malloy, P.F. (2002). Frontal Systems Behavior Scale. Professional Manual. Lutz, FL: PAR Inc.

Hart, T. \& Sherer, M. (2005). Preface to Special Edition. Journal of Head Trauma Rehabilitation, 20, 285-286.

Hart, T., Giovannetti, T., Montgomery, M.W., \& Schwartz, M.F. (1998). Awareness of errors in naturalistic action after traumatic brain injury. Journal of Head Trauma Rehabilitation, 13, 16-28.

Hart, T., Whyte, J., Kim, J., \& Vaccaro, M. (2005). Executive Function and Self-awareness of "Real-world" Behavior and Attention Deficits Following Traumatic Brain Injury. Journal of Head Trauma Rehabilitation, 20, 333-347.

Hoofien, D., Gilboa, A., Vakil, E., \& Barak, O. (2004). Unawareness of cognitive deficits and daily functioning among persons with traumatic brain injuries. Journal of Clinical and Experimental Neuropsychology, 26, 278-290.

Lam, C.S., McMahon, B.T., Priddy, D.A., \& Gehred-Schultz, A. (1988). Deficit awareness and treatment performance among traumatic head injury adults. Brain Injury, 2, 235-242.

Levine, B., Dawson, D., Boutet, I., Schwartz, M.L., \& Stuss, D.T. (2000). Assessment of strategic self-regulation in traumatic brain injury: Its relationship to injury severity and psychosocial outcome. Neuropsychology, 14, 491-500.

Malec, J.F., Machulda, M.M., \& Moessner, A.M. (1997). Differing problem perceptions of staff, survivors, and significant others after brain injury. Journal of Head Trauma Rehabilitation, 12, 1-13.

Manly, T., Owen, A.M., McAvinue, L., Datta, A., Lewis, G.H., Scott, S.K., Rorden, C., Pickard, J., \& Robertson, I.H. (2003). Enhancing the sensitivity of a sustained attention task to fron- tal damage: Convergent clinical and functional imaging evidence. Neurocase, 9, 340-349.

Markova, I.S. \& Berrios, G.E. (2001). The "object" of insight assessment: Relationship to insight "structure." Psychopathology, 34, 245-252.

McAvinue, L., O’Keeffe, F., McMackin, D., \& Robertson, I.H. (2005). Impaired sustained attention and error awareness in traumatic brain injury: Implications for insight. Neuropsychological Rehabilitation, 15, 569-587.

McGlynn, S.M. \& Schacter, D.L. (1989). Unawareness of deficits in neuropsychological syndromes. Journal of Clinical and Experimental Neuropsychology, 11, 143-205.

Mehrabian, A. \& Epstein, N. (1972). A measure of emotional empathy. Journal of Personality, 40, 525-543.

Nelson, H.E. (1982). The National Adult Reading Test (NART): Test Manual (1st ed.). Windsor: NFER-Neslon.

Nelson, H.E. \& Willison, J. (1991). The National Adult Reading Test Manual (2nd ed.). Windsor: NFER-Nelson.

Noe, E., Ferri, J., Caballero, M.C., Villodre, R., Sanchez, A., \& Chirivella, J. (2005). Self-awareness after acquired brain injury: Predictors and rehabilitation. Journal of Neurolology, 252, $168-175$.

O'Keeffe, F., Dockree, P., \& Robertson, I.H. (2004). Poor insight in traumatic brain injury mediated by impaired error processing? Evidence from electrodermal activity. Brain Research. Cognitive Brain Research, 22, 101-112.

Ownsworth, T., Clare, L., \& Morris, R. (In Press). An integrated biopsychosocial approach to understanding awareness deficits in Alzheimer's disease and brain injury. Neuropsychological Rehabilitation.

Ownsworth, T. \& Fleming, J. (2005). The relative importance of metacognitive skills, emotional status, and executive function in psychosocial adjustment following acquired brain injury. Journal of Head Trauma Rehabilitation, 20, 315-332.

Ownsworth, T.L., McFarland, K., \& Young, R.M. (2002). The investigation of factors underlying deficits in self-awareness and self-regulation. Brain Injury, 16, 291-309.

Ownsworth, T.L., McFarland, K.M., \& Young, R.M. (2000). Development and standardization of the Self-regulation Skills Interview (SRSI): A new clinical assessment tool for acquired brain injury. Clinical Neuropsychology, 14, 76-92.

Prigatano, G.P. (1996). Behavioral limitations TBI patients tend to underestimate: A replication and extension to patients with laterlized cerebral dysfunction. Clinical Neuropsychologist, 10, 191-201.

Prigatano, G.P. (1999). Disorders of self-awareness after brain injury. In G.P. Prigatano (Ed.), Principles of Neuropsychological Rehabilitation (pp. 265-293). New York: Oxford University Press.

Prigatano, G.P. (2005). Disturbances of self-awareness and rehabilitation of patients with traumatic brain injury: A 20-year perspective. Journal of Head Trauma Rehabilitation, 20, 19-29.

Prigatano, G.P. \& Altman, I.M. (1990). Impaired awareness of behavioral limitations after traumatic brain injury. Archives of Physiology and Medical Rehabilitation, 71, 1058-1064.

Prigatano, G.P., Altman, I.M., \& O’Brien, K.P. (1990). Behavioral limitations that traumatic-brain-injured patients tend to underestimate. Clinical Neuropsychologist, 4, 163-176.

Prigatano, G.P., Borgaro, S., Baker, J., \& Wethe, J. (2005). Awareness and distress after traumatic brain injury: A relative's perspective. Journal of Head Trauma Rehabilitation, 20, 359-367. 
Prigatano, G.P., Bruna, O., Mataro, M., Munoz, J.M., Fernandez, S., \& Junque, C. (1998). Initial disturbances of consciousness and resultant impaired awareness in Spanish patients with traumatic brain injury. Journal of Head Trauma Rehabilitation, 13, 29-38.

Prigatano, G.P. \& Fordyce, D.J. (1986). Cognitive dysfunction and psychosocial adjustment after brain injury. In G.P. Prigatano (Ed.), Neuropsychological Rehabilitation after Brain Injury. Baltimore: John Hopkins University Press.

Prigatano, G.P., Fordyce, D.J., \& Zeiner, H.K. (1986). Neuropsychological Rehabilitation After Brain Injury. Baltimore: John Hopkins University Press.

Prigatano, G.P., Ogano, M., \& Amakusa, B. (1997). A crosscultural study on impaired self-awareness in Japanese patients with brain dysfunction. Neuropsychiatry Neuropsychology and Behavioral Neurology, 10, 135-143.

Prigatano, G.P. \& Schacter, D.L. (1991). Awareness of Deficit after Brain Injury: Clinical and Theoretical Issues. New York: Oxford University Press.

Robertson, I.H., Manly, T., Andrade, J., Baddeley, B.T., \& Yiend, J. (1997). “Oops!”: Performance correlates of everyday attentional failures in traumatic brain injured and normal subjects. Neuropsychologia, 35, 747-758.

Robertson, I.H., Ward, T., Ridgeway, V., \& Nimmo-Smith, I. (1996). The structure of normal human attention: The Test of Everyday Attention. Journal of the International Neuropsychological Society, 2, 525-534.

Sawchyn, J.M., Mateer, C.A., \& Suffield, J.B. (2005). Awareness, emotional adjustment, and injury severity in postacute brain injury. Journal of Head Trauma Rehabilitation, 20, 301-314.

Schacter, D.L. (1990). Toward a cognitive neuropsychology of awareness: Implicit knowledge and anosognosia. Journal of Clinical and Experimental Neuropsychology, 12, 155-178.

Schmitz, T.W., Rowley, H.A., Kawahara, T.N., \& Johnson, S.C. (2006). Neural correlates of self-evaluative accuracy after traumatic brain injury. Neuropsychologia, 44, 762-773.

Sherer, M., Bergloff, P., Boake, C., High, W., Jr., \& Levin, E. (1998a). The Awareness Questionnaire: Factor structure and internal consistency. Brain Injury, 12, 63-68.

Sherer, M., Bergloff, P., Levin, E., High, W.M., Jr., Oden, K.E., \& Nick, T.G. (1998b). Impaired awareness and employment outcome after traumatic brain injury. Journal of Head Trauma and Rehabilitation, 13, 52-61.
Sherer, M., Boake, C., Levin, E., Silver, B., Ringholz, G., \& High, W.M., Jr. (1998c). Characteristics of impaired awareness after traumatic brain injury. Journal of the International Neuropsychological Society, 4, 380-387.

Sherer, M., Hart, T., Whyte, J., Nick, T.G., \& Yablon, S.A. (2005). Neuroanatomic basis of impaired self-awareness after traumatic brain injury: Findings from early computed tomography. Journal of Head Trauma and Rehabilitation, 20, 287-300.

Sohlberg, M.M., Mateer, C.A., Penkman, L., Glang, A., \& Todis, B. (1998). Awareness intervention: Who needs it? Journal of Head Trauma and Rehabilitation, 13, 62-78.

Spreen, O. \& Benton, A.L. (1969). Neurosensory Center Comprehensive Examination for Aphasia (NCCEA). Victoria: University of Victoria Neuropsychology Laboratory.

Spreen, O. \& Strauss, E. (1998). A Compendium of Neuropsychological Tests. Administration, Norms and Commentary (2nd ed.). New York: Oxford University Press.

Stuss, D.T., Picton, T.W., \& Alexander, M.P. (2001). Consciousness, self-awareness and the frontal lobes. In S. Salloway, P. Malloy, \& J. Duffy (Eds.), The Frontal Lobes and Neuropsychiatric Illness. Washington, DC: American Psychiatric Press.

Toglia, J. \& Kirk, U. (2000). Understanding awareness deficits following brain injury. NeuroRehabilitation, 15, 57-70.

Trudel, T.M., Tryone, W.W., \& Purdum, C.M. (1998). Awareness of disability and long-term outcome after traumatic brain injury. Rehabilitation Psychology, 43, 267-281.

Walker, D. (2003). Remembrance of things future: Involuntary and strategic processes in prospective memory reminders. Unpublished PhD, University of Reading, Reading, UK.

Wallace, C.A. \& Bogner, J. (2000). Awareness of deficits: Emotional implications for persons with brain injury and their significant others. Brain Injury, 14, 549-562.

Wechsler, D., Wycherly, R., Benjamin, L., Crawford, J.R., \& Mockler, D. (1998). Wechsler Memory Scale-111 (3rd ed.). London: The Psychological Corporation Limited.

Wise, K., Ownsworth, T. \& Fleming, J. (2005). Convergent validity of self-awareness measures and their association with employment outcome in adults following acquired brain injury. Brain Injury, 19, 765-775.

Zigmond, A.S. \& Snaith, R.P. (1983). The hospital anxiety and depression scale. Acta Psychiatr Scand, 67, 361-370. 